\title{
Direct and Indirect Excitation of Laterodorsal Tegmental Neurons by Hypocretin/Orexin Peptides: Implications for Wakefulness and Narcolepsy
}

\author{
Sophie Burlet, Christopher J. Tyler, and Christopher S. Leonard \\ Department of Physiology, New York Medical College, Valhalla, New York 10595
}

Compelling evidence links the recently discovered hypothalamic peptides Hypocretin/Orexin (Hcrt/Orx) to rapid eye movement sleep (REM) control and the sleep disorder narcolepsy, yet how they influence sleep-related systems is not well understood. We investigated the action of Hcrt/Orx on mesopontine cholinergic (MPCh) neurons of the laterodorsal tegmental nucleus (LDT), a target group whose function is altered in canine narcolepsy and appears pivotal for normal REM and wakefulness. Extracellular recordings from mouse brainstem slices revealed that Hcrt/Orx evoked prolonged firing of LDT neurons. Whole-cell recordings revealed that Hcrt/Orx had actions on both presynaptic neurons and at postsynaptic sites. Hcrt/Orx produced an increase in frequency and amplitude of spontaneous EPSCs without equivalent effect on IPSCs, by triggering action potentials and enhancing spike-evoked synaptic transmission in glutamatergic afferents. Postsynaptically, Hcrt/Orx produced an inward current and an increase in membrane current noise, which were accompanied by a conductance increase. These persisted in TTX, ionotropic glutamate receptor antagonists, and low extracellular calcium. Both presynaptic and postsynaptic actions were specific because they were not mimicked by an Hcrt/Orx fragment, and both actions were observed for cholinergic and noncholinergic LDT neurons. Finally, extracellular recordings during postsynaptic potential blockade demonstrated that postsynaptic actions of Hcrt/Orx alone could evoke prolonged firing. In the context of other recent work, our findings suggest that Hcrt/Orx neurons may coordinate the activity of the entire reticular activating system during waking. Moreover, these findings address specific hypotheses regarding the cellular mechanisms underlying REM disregulation in narcolepsy.

Key words: REM sleep; orexin; hypocretin; narcolepsy; mesopontine cholinergic neurons; reticular formation; nitric oxide synthase; whole cell; slice
The Hypocretin/Orexin (Hcrt/Orx) peptide system consists of two peptides (Hcrt/Orx-A and Hcrt/Orx-B) derived from a single prepro-peptide (de Lecea et al., 1998; Sakurai et al., 1998) and two high-affinity G-protein-coupled receptors (Hcrt/OrxR1 and Hcrt/OrxR2) (Sakurai et al., 1998) (for review, see Kilduff and Peyron, 2000; Willie et al., 2001). Hcrt/Orx-synthesizing neurons are localized to the lateral hypothalamus and were initially hypothesized to function in the control of feeding (de Lecea et al., 1998; Sakurai et al., 1998). This system was linked recently to the control of sleep and wakefulness by the surprising discovery that its genetic disruption produces narcolepsy (Chemelli et al., 1999; Lin et al., 1999), a sleep disorder characterized by excessive daytime sleepiness, sleep fragmentation, and the intrusion of rapid eye movement (REM) sleep behaviors into wakefulness (for review, see Nishino and Mignot, 1997). The loss of Hcrt/Orx also appears central to human narcolepsy (Nishino et al., 2000; Peyron et al., 2000; Thannickal et al., 2000).

A role for Hcrt/Orx neurons in behavioral-state control was anticipated (Peyron et al., 1998) from their projection pattern, which includes the locus ceruleus, the raphe nuclei, and the basal forebrain and mesopontine cholinergic (MPCh) groups (Peyron

\footnotetext{
Received Sept. 20, 2001; revised Jan. 11, 2002; accepted Jan. 15, 2002.

This work was supported by National Institutes of Health Grants NS27881 and HL64150. We thank Drs. K. Kohlmeier, R. Chemelli, and C. Thompson for helpful discussions of the data and Drs. K. Kohlmeier, W. Ross, and B. Rudy for comments on a previous version of this manuscript.

Correspondence should be addressed to Dr. Christopher S. Leonard, Department of Physiology, New York Medical College, Basic Science Building, Valhalla, NY 10595. E-mail: chris_leonard@nymc.edu.

Copyright (ㄷ) 2002 Society for Neuroscience $\quad 0270-6474 / 02 / 222862-11 \$ 15.00 / 0$
}

et al., 1998; Chemelli et al., 1999; Date et al., 1999; Horvath et al., 1999; Nambu et al., 1999). Moreover, intracerebroventricular delivery of Hcrt/Orx-A enhances arousal and reduces REM sleep (Hagan et al., 1999; Piper et al., 2000), and significant Hcrt/OrxR mRNA levels are found in locus ceruleus, the raphe nuclei, and mesopontine cholinergic nuclei (Trivedi et al., 1998; Marcus et al., 2001).

However, only limited information exits about the cellular action of these peptides in the CNS. Activation of Hcrt/OrxRs expressed in human embryonic kidney 293 cells increases intracellular calcium (Sakurai et al., 1998), and a similar effect was demonstrated in cultured hypothalamic (van den Pol et al., 1998) and spinal neurons (van den Pol, 1999). Hcrt/Orx-B also increases both glutamatergic and GABAergic synaptic input (de Lecea et al., 1998) to cultured hypothalamic neurons (van den Pol et al., 1998). In brain slices, Hcrt/Orx excites locus ceruleus (Hagan et al., 1999; Horvath et al., 1999) and dorsal raphe neurons (Brown et al., 2001), and, in vivo, application in the locus ceruleus increases firing and enhances behavioral arousal (Bourgin et al., 2000).

To further understand how this peptide system interacts with brainstem systems controlling behavioral state, we investigated the action of Hcrt/Orx on neurons of the laterodorsal tegmental nucleus (LDT) in brain slices. Cholinergic neurons of this nucleus, and the adjacent pedunculopontine tegmental nucleus provide the major cholinergic input to the thalamus (for review, see Wainer and Mesulam, 1990) and the medial pontine reticular formation (mPRF) (Mitani et al., 1988). Activity of these neurons is linked to REM sleep and arousal (for review, see Steriade and 
McCarley, 1990) and can profoundly influence thalamocortical processing (Curro Dossi et al., 1991; Steriade et al., 1996). Moreover, studies on narcoleptic canines implicate these neurons in generating the attacks of muscle atonia (cataplexy) characteristic of this disorder (Reid et al., 1994a,b).

Our results demonstrate for the first time that Hcrt/Orx peptides excite both cholinergic and noncholinergic neurons of the LDT by both direct actions and actions on their afferents. These findings have implications for the role of the Hcrt/Orx system in the control of wakefulness and for the neural mechanisms underlying REM sleep and cataplexy.

Parts of this work have been published previously in abstract form (Burlet et al., 2000).

\section{MATERIALS AND METHODS}

Slice preparation and extracellular solutions. Brain slices were prepared from 14- to 32-d-old C57BL/6 mice (Taconic, Germantown, NY; Charles River Laboratories, Wilmington, MA). All procedures complied with National Institutes of Health and institutional guidelines for ethical use of animals. After the induction of deep anesthesia with isofluorane, mice were decapitated, and brains were rapidly removed into an ice-cold artificial CSF (ACSF) that contained (in $\mathrm{mM}$ ): $121 \mathrm{NaCl}, 5 \mathrm{KCl}, 1.2$ $\mathrm{NaH} 2 \mathrm{PO}_{4}, 2.7 \mathrm{CaCl}_{2}, 1.2 \mathrm{MgSO}_{4}, 26 \mathrm{NaHCO}_{3}, 20$ dextrose, and 4.2 lactic acid, oxygenated by bubbling with carbogen $\left(95 \% \mathrm{O}_{2}\right.$ and $5 \%$ $\mathrm{CO}_{2}$ ). The brainstem was blocked in a coronal plane, and vibratome sectioned (VT1000S; Leica, Nussloch, Germany) into 350- $\mu$ m-thick sections. Slices containing the LDT were incubated at $35^{\circ} \mathrm{C}$ for $15 \mathrm{~min}$ in oxygenated ACSF and were then stored at room temperature until they were transferred to a submerged recording chamber, which was perfused at $3-5 \mathrm{ml} / \mathrm{min}$ with oxygenated $\mathrm{ACSF}$ at room temperature. In some experiments, calcium-dependent processes were inhibited by reducing extracellular calcium to $\sim 20 \mu \mathrm{M}$ (calculated with Patcher's Power Tools for Igor Pro; WaveMetrics, Lake Oswego, OR) by adding 2.7 mM EGTA to the ACSF and elevating $\mathrm{MgSO}_{4}$ to either 3.9 or $6 \mathrm{~mm}$.

Electrophysiological recordings. Neurons were visualized $(160-200 \times)$ with near-infrared light $(>775 \mathrm{~nm})$ transillumination, using a nuvicon tube camera (VE-1000; Dage-MTI, Michigan City, IN) and the differential interference contrast optics of a fixed-stage microscope (BX50W I; Olympus Optical, Tokyo, Japan). Cells were selected for whole-cell recording from a region identified as LDT at low magnification. Neurons were recorded in voltage-clamp mode using an Axopatch 200A or B amplifier (Axon Instruments, Foster City, CA). Giga-seal whole-cell recordings (Hamill et al., 1981) were made with pipettes pulled from 1.5-mm-diameter glass capillary tubing (Corning 7052; A\&M Systems, Carlsborg, WA) using a horizontal multistep puller (P87; Sutter Instruments, Novato, CA). Voltage-clamp recordings were made to study EPSCs using a pipette solution containing (in mM): $144 \mathrm{~K}$-gluconate, 0.2 EGTA, $3 \mathrm{MgCl}_{2}$, $10 \mathrm{HEPES}, 0.3 \mathrm{NaGTP}$, and $4 \mathrm{Na}_{2}$ ATP. IPSCs were recorded using an internal solution with $\mathrm{KCl}$ substituted for K-gluconate so that IPSCs were inward at resting membrane potential. Biocytin $(0.1 \%)$ and Na-GTP were added to the pipette solution just before use. "Loose-patch" (100-300 M $\Omega$ ) voltage recordings of extracellular activity were made in current-clamp mode from somata of visualized neurons with the same pipettes used for whole-cell recordings but were filled with extracellular solution. Membrane currents and voltages were recorded with respect to an $\mathrm{Ag} / \mathrm{AgCl}$ reference electrode located near the outflow of the chamber. Whole-cell liquid junction potentials were calculated to be approximately $-12 \mathrm{mV}$ for our internal solutions, and membrane potentials were not corrected.

Membrane voltages and currents were controlled and recorded with a computer running pClamp8 software (Axon Instruments). Access resistance $\left(R_{\text {acc }}\right)$ was estimated on-line by exponential fitting of the uncompensated capacitative transients resulting from $\pm 2.5 \mathrm{mV}$ voltage steps delivered at $3.3 \mathrm{~Hz}$ using the built-in membrane test routine of pClamp8. The quality of recorded cells were simultaneously assessed with this routine by monitoring input resistance, holding current, and capacitance. Parameters were monitored continuously over the initial several minutes after establishing the whole-cell configuration and then again throughout the experiment before and after each protocol. Recordings were terminated if the estimated $R_{\text {acc }}$ was $>30 \mathrm{M} \Omega$, became unstable, or changed by $>20 \%$ between measurements. Recordings were also terminated if cell parameters became unstable. Recordings were uncompensated for series resistance errors because the recorded currents and associated voltage errors were small. Voltage measurements were filtered at $10 \mathrm{kHz}$ with the four-pole Bessel filter at the amplifier output and sampled at 20 $\mathrm{kHz}$, whereas EPSCs and IPSCs were filtered at $2 \mathrm{kHz}$ and sampled at $5 \mathrm{kHz}$. Detection of PSCs and some analyses were done using Mini Analysis software (Synaptosoft, Decatur, GA). To compare the effects of Hcrt/Orx on the frequency and amplitudes of PSCs, epochs of at least 100 sec were used before, during, and after superfusion. Cumulative distributions of EPSCs or IPSCs were then compared using KolmogorovSmirnov statistics with Mini Analysis software. Additional analysis and figure preparation was done using Igor Pro software (WaveMetrics). Differences between means were compared using a two-sample, twotailed $t$ test corrected for multiple comparisons (when necessary) and repeated-measures ANOVA using DataDesk 6 software (Data Description, Ithaca, NY). Numerical results are reported as mean \pm SEM.

Spike-evoked EPSCs were elicited with single, near-minimal electrical stimuli $(0.1-0.2 \mathrm{msec}$ duration; $0.2-0.33 \mathrm{~Hz})$ from an optically isolated stimulator (A35OD-A; World Precision Instruments, Sarasota, FL). Stimuli were delivered with a bipolar tungsten microelectrode having a single sharpened pole (TM33B01KT; World Precision Instruments) located $\sim 1 \mathrm{~mm}$ in front of the other. The sharp end of the electrode was positioned just below the slice surface $\sim 30-50 \mu \mathrm{m}$ from a proximal dendrite of the recorded neuron. Stimulator voltage was increased until an evoked EPSC (evEPSC) appeared. These typically had sharp thresholds, had a smooth rising phase that arose after a distinct delay, showed little latency jitter, and showed significant amplitude fluctuations and failures. To study the action of Hcrt/Orx, current strength was typically increased to $\sim 10 \%$ above threshold. This did not produce shape changes in those evEPSCs examined and suggested that these arose from single fibers. Amplitude distributions of 30-50 consecutive evEPSCs were compared statistically using Kolmogorov-Smirnov statistics. Average values of evEPSCs were expressed as mean \pm SEM of these 30-50 events.

Reagents. Orexin-B peptide was purchased from American Peptide (Sunnyvale, CA), and Orexin-A peptide was purchased from American Peptide, Phoenix Pharmaceuticals (Mountain View, CA), and Sigma (St. Louis, MO). Peptides were applied by bath superfusion (at $10 \mathrm{nM}, 100$ $\mathrm{nM}, 300 \mathrm{nM}$, or $1 \mu \mathrm{M}$ ). An amide fragment of Orexin-A (peptide sequence 16-33; Phoenix Pharmaceuticals) was dissolved in normal ACSF and superfused at $1 \mu \mathrm{M}$ as a control for nonspecific peptide actions. In some experiments, TTX ( $0.5 \mu \mathrm{M}$; Alomone Labs, Jerusalem, Israel) was added to the recording solutions to block voltage-gated $\mathrm{Na}^{+}$channels. Ionotropic glutamate receptor antagonists 6,7-dinitroquinoxaline-2,3-dione (DNQX) $(15 \mu \mathrm{M})$ and 2-amino-5-phosphonopentanoic acid (APV) (50 $\mu \mathrm{M})$, ionotropic GABA receptor antagonists picrotoxin $(10 \mu \mathrm{M})$ and bicuculline $(10 \mu \mathrm{M})$, and the glycine receptor antagonist strychnine (2.5 $\mu \mathrm{M})$ were also used in some experiments (Sigma).

Immunohistochemistry. Cholinergic neurons in the LDT selectively colocalize the enzyme brain nitric oxide synthase (bNOS) (Vincent and Kimura, 1992) and were identified in this study by immunohistochemical labeling for bNOS. Slices were fixed in $4 \%$ paraformaldehyde for $2-20 \mathrm{~d}$ at $4{ }^{\circ} \mathrm{C}$, incubated in $30 \%$ sucrose in $0.1 \mathrm{M}$ PBS overnight, and resectioned at $40 \mu \mathrm{m}$ using a freezing microtome. Sections were incubated in avidinTexas Red (1:250 in PBS containing 0.3\% Triton X-100; Vector Laboratories, Burlingame, CA) to visualize the recorded cell. Sections were then incubated, in succession, in monoclonal bNOS antibodies (1:400 in phosphate buffer containing $1 \%$ bovine serum albumin and $0.3 \%$ Triton $\mathrm{X}-100$ at room temperature; Sigma) and FITC-conjugated goat antimouse IgGs (1:50 in PBS; Chemicon, Temecula, CA) to determine whether recorded cells were bNOS immunoreactive. The sections were mounted on glass slides, dried, dehydrated, and coverslipped, and then 48-bit color images were acquired using a cooled CCD camera (Coolsnap; Roper Scientific, Trenton, NJ) mounted on an epi-fluorescence microscope (BX60; Olympus Optical) equipped with a $100 \mathrm{~W}$ mercury illuminator. Fluorophores were visualized using the Chroma (Brattleboro, VT) HiQ FITC (41001) and HiQ Texas Red (41004) filter sets.

\section{RESULTS}

\section{Hypocretin/orexin stimulated repetitive firing in LDT neurons}

Initially, we evaluated possible actions of Hcrt/Orx using loosepatch extracellular recordings from the somata of visualized LDT neurons. Neurons recorded in this manner had very low or zero spontaneous firing rates (assessed over $100 \mathrm{sec}$ ). Bath application 


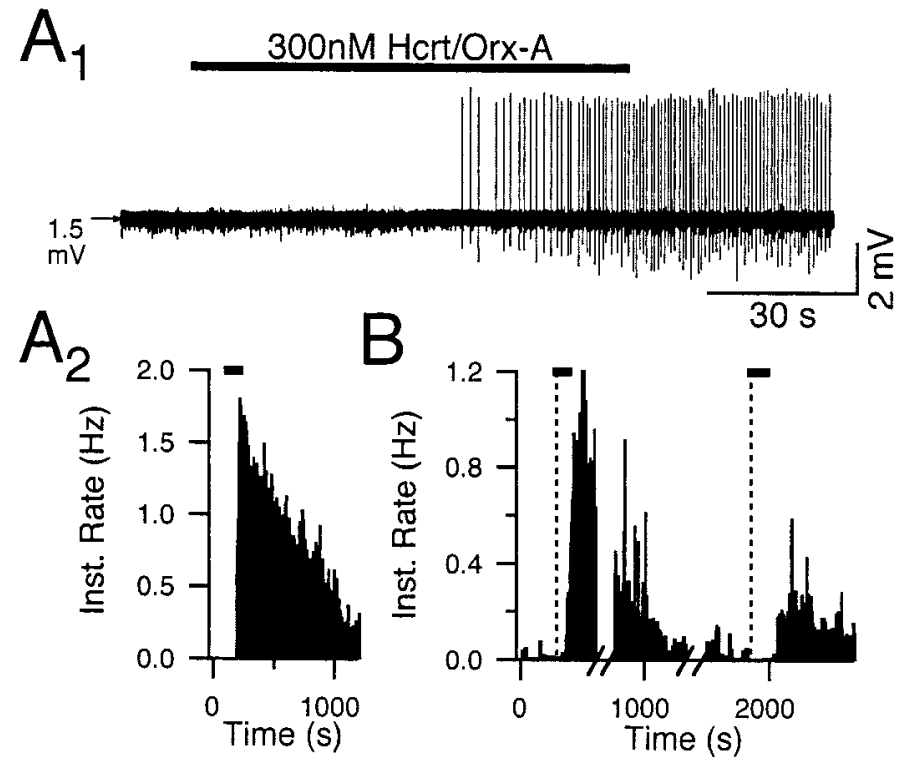

Figure 1. Hcrt/Orx stimulated a long-lasting increase in firing of LDT neurons in vitro. $A_{1}$, Extracellular loose-patch voltage recordings indicated that Hcrt/Orx-A ( $300 \mathrm{nM})$ stimulated even quiescent neurons to fire repetitively. $A_{2}$, Instantaneous spike rate of the neuron in $A_{1}$ shows the long-lasting Hcrt/Orx response. The bar over the histogram indicates the duration of the superfusion in this and subsequent figures. $B$, Instantaneous firing rate from another neuron before and after two Hcrt/Orx applications $(1 \mu \mathrm{M})$ shows that the second response was greatly attenuated. Note that the breaks in the time axis correspond to the time between data files in this and subsequent figures.

of Hcrt/Orx-A (300 nм or $1 \mu \mathrm{M}$; $1-2 \mathrm{~min}$ ) produced a long-lasting increase in firing in all cases $(n=15)$ (Fig. $1 A)$, driving even quiescent neurons into repetitive firing. On average, $1 \mu \mathrm{M} \mathrm{Hcrt/}$ Orx increased firing from a baseline of $0.06 \pm 0.02$ spikes/sec to a peak of $1.02 \pm 0.22 \mathrm{spikes} / \mathrm{sec}(n=6)$. We also noted that a second application of Hcrt/Orx produced a response that was smaller than the first, even after firing had recovered to near baseline levels (Fig. 1B), suggesting some form of use dependence or desensitization.

\section{Hcrt/Orx-A and Hcrt/Orx-B excited bNOS- immunopositive LDT neurons by multiple actions}

To investigate whether this excitation was mediated by presynaptic or postsynaptic mechanisms, whole-cell voltage-clamp recordings were obtained from the somata of 75 LDT neurons having a mean input resistance of $356.1 \pm 24.4 \mathrm{M} \Omega$ (range, 106.4 to 1100 $\mathrm{M} \Omega)$. Hcrt/Orx-A or $-\mathrm{B}(1 \mu \mathrm{M}, n=17 ; 300 \mathrm{nM}, n=7)$ was superfused while neurons were held near resting potential $(-60$ $\mathrm{mV})$ in the presence of picrotoxin $(10 \mu \mathrm{M} 77)$ or bicuculline (10 $\mu \mathrm{M})$ and strychnine $(2.5 \mu \mathrm{M})$ to block spontaneous IPSCs. Under these conditions, both peptides produced an increase in synaptic activity and a small, slow inward shift in the holding current. These effects are illustrated for a bNOS-immunopositive $\left(\mathrm{bNOS}^{+}\right.$) LDT neuron in Figure $2 A$ in response to superfusion of Hcrt/Orx-A $(1 \mu \mathrm{M})$. Brief epochs of membrane current from before and after Hcrt/Orx application are illustrated below in Figure 2, $B$ and $C$, to show the synaptic activity more clearly. These data also illustrate the slow inward current. Both the EPSC activity and the inward current recovered by 22 min after Hcrt/ Orx-A application (Fig. 2 $B_{3}$ )

To quantify the effect of Hcrt/Orx on spontaneous EPSCs (sEPSCs), cumulative amplitude and interval distributions were compared for each condition. For the example illustrated in Figure 2, the average sEPSC amplitude increased from -20.4 to $-33.6 \mathrm{pA}(p<0.0001)$ (Fig. $2 C$, left $)$, and the average interval decreased from 418.1 to $101.6 \mathrm{msec}(p<0.0001)$ (Fig. $2 C$, right), verifying that the sEPSC frequency dramatically increased. This increase in sEPSC frequency was typical of the cells recorded. Hcrt/Orx-A at $1 \mu \mathrm{M}$ increased the frequency $(p<0.001)$ for 12 of 12 cells (mean interval, $47.6 \pm 6.8 \%$ of control), and $1 \mu \mathrm{M}$ Hcrt/Orx-B increased the frequency $(p<0.001)$ for three of five cells (mean interval, $56.2 \pm 3.0 \%$ of control). Moreover, $300 \mathrm{~nm}$ Hcrt/Orx-A increased the mean frequency of sEPSCs for six of seven neurons (mean interval, $50.7 \pm 8.6 \%$ of control) by an amount not different from that produced by $1 \mu \mathrm{M}$ Hcrt/Orx. Thus, at the two concentrations tested, Hcrt/Orx peptides doubled the mean frequency of sEPSC in $>85 \%$ of LDT neurons.

In neurons that showed an increase in sEPSC frequency, the average amplitude of the sEPSCs was also increased after both 1 $\mu \mathrm{M}$ and $300 \mathrm{nM}$ Hcrt/Orx to $134.3 \pm 9.3 \%(n=15)$ and $110.0 \pm$ $14.0 \%(n=6)$ of control, respectively. However, an increase in sEPSC amplitude was observed for only a subset of neurons. A significant increase in mean sEPSC amplitude was found for nine of 15 neurons tested with $1 \mu \mathrm{M}$ Hcrt/Orx-A and for two of six neurons tested with $300 \mathrm{~nm}$ Hcrt/Orx-A. Thus, an increase in mean sEPSC amplitude was not a prerequisite for an increase in sEPSC frequency. In some neurons, recordings were long enough to determine that these amplitude and frequency effects recovered after the washout of Hcrt/Orx $(n=6)$. The average amplitude and interval data for $1 \mu \mathrm{M}$ Hcrt/Orx are summarized in Figure 2D.

We confirmed that the stimulated EPSCs were glutamatergic in experiments in which Hcrt/Orx was applied after ionotropic glutamate receptors were blocked $(n=4)$ (Fig. $2 E)$. Under these conditions, Hcrt/Orx evoked an inward current but no PSCs. The magnitude of the inward current produced by $1 \mu \mathrm{M}$ Hcrt/Orx-A was $-17.3 \pm 2.7 \mathrm{pA}(n=12)$, whereas $1 \mu \mathrm{M}$ Hcrt/Orx-B produced an average inward current of $-16.8 \pm 1.1 \mathrm{pA}(n=3)$. Similarly, $300 \mathrm{~nm}$ Hcrt/Orx-A produced an inward current of $-24.1 \pm 8.4$ pA $(n=6)$, which was not different from that evoked by $1 \mu \mathrm{M}$ Hcrt/Orx $(p=0.34)$. These recordings also demonstrated that there was a substantial increase in membrane current noise that accompanied the inward current and was distinct from the fast PSCs (Fig. 2E). At its peak effect, $1 \mu \mathrm{M}$ Hcrt/Orx-A increased the average rms noise to $133.4 \pm 9.1 \%$ of control $(n=12)$. Thus, Hcrt/Orx peptides had multiple actions on LDT neurons.

\section{Excitatory effects of Hcrt/Orx-A required the full peptide}

To test the possibility that these actions of Hcrt/Orx resulted from a nonspecific effect of the peptide, we compared the actions in six LDT neurons of the amide fragment of Orexin-A (16-33), which lacks the two intrachain disulfide bonds of the full peptide (Fig. 3 ). First the fragment $(1 \mu \mathrm{M})$ was superfused (Fig. $3 A$ ), and then the full peptide $(1 \mu \mathrm{M})$ was superfused (Fig. $3 B)$. None of the fragment applications produced an increase in sEPSC frequency, whereas each of the Hcrt/Orx-A applications resulted in a significant increase in sEPSC frequency (average mean interval, $58.5 \pm$ $8.3 \%$ of control). Moreover, the average sEPSC amplitude increased after Hcrt/Orx application (138.8 $\pm 20.8 \%$ of control) but did not after fragment application (99.1 $\pm 4.3 \%$ of control). Unexpectedly, the fragment did produce a reduction in the average sEPSC frequency in three of six cases (average mean interval, $150.8 \pm 20.7 \%$ of control). We also found that the fragment did 


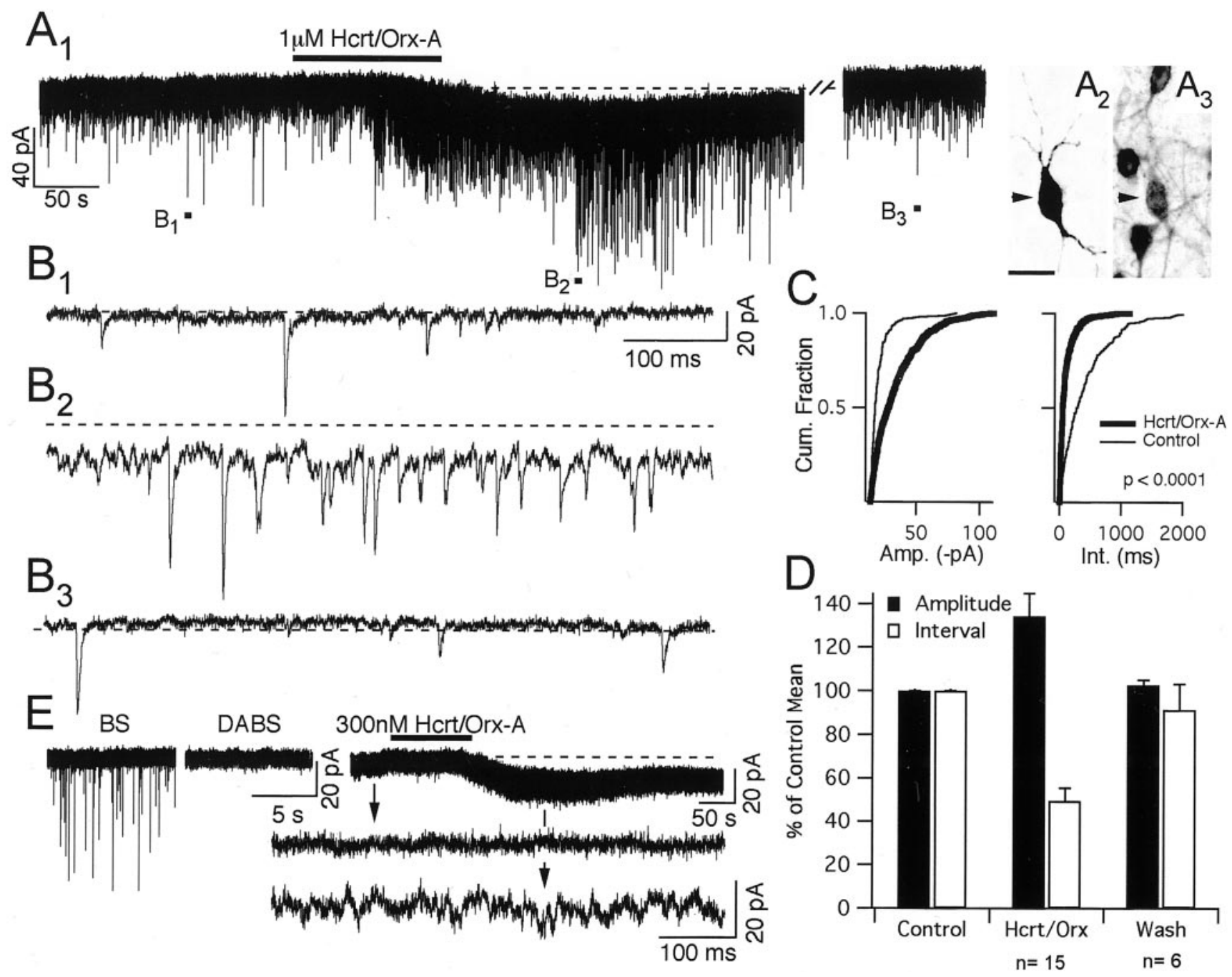

Figure 2. Hcrt/Orx produced an increase in glutamatergic synaptic activity, an inward current, and an increase in membrane current noise. $A_{l}$, Whole-cell recordings of membrane current at $-60 \mathrm{mV}$ in the presence of bicuculline $(10 \mu \mathrm{M})$ and strychnine $(2.5 \mu \mathrm{M})$ indicate that Hcrt/Orx-A $(1 \mu \mathrm{M})$ application produced a large increase in SEPSC activity and an inward shift of the baseline current that reversed after a washout of $\sim 20$ min. $A_{2}$, Arrow indicates the neuron whose currents are shown in $A-C$. The neuron was filled with biocytin during the recording and visualized with avidin-Texas Red epifluorescence. $A_{3}$, The same neuron was also visible with FITC immunofluorescence for bNOS. Scale bar (in $\left.A_{2}\right): A_{2}, A_{3}, 25 \mu \mathrm{m}$. $B_{1}$, An expanded segment of the trace in $A_{1}$ before Hcrt/Orx application (labeled $B_{1}$ in $A_{1}$ ). $B_{2}$, Expanded segment from $A_{1}$ after Hcrt/Orx-A application illustrates the greater number of sEPSCs and the inward current shift compared with baseline (horizontal dashed line). $B_{3}$, These effects recovered by 20 min after the end of the Hcrt/Orx application. $C$, Cumulative distributions of sEPSC amplitudes (left; Amp) and intervals (right; Int) from before (thin line) and after (thick line) Hcrt/Orx-A application. Kolmogorov-Smirnov statistics demonstrated that Hcrt/Orx-A significantly increased both amplitude and frequency of sEPSCs. $D$, Population means of sEPSC amplitudes (black bars) and inter-event intervals (white bars) from 15 LDT neurons expressed as percentage of control values. Each neuron showed a significant reduction in the inter-event interval distribution after $1 \mu \mathrm{M} \mathrm{Hcrt/Orx-A.} \mathrm{For} \mathrm{six} \mathrm{of} \mathrm{these} \mathrm{cells,} \mathrm{sufficient} \mathrm{recording} \mathrm{time} \mathrm{was} \mathrm{available} \mathrm{to} \mathrm{observe}$ a recovery after washout of the peptide. $E$, EPSCs recorded in the presence of bicuculline and strychnine $(l e f t ; B S)$ were entirely abolished by the addition of DNQX and APV (middle; DABS). Subsequent application of Hcrt/Orx (300 nM) produced an inward current but no additional PSCs. A substantial increase in current noise accompanied the inward current. Arrows point to expanded sections of the trace before and after Hcrt/Orx to illustrate the noise at higher time resolution. The time scale in the middle also applies to the left. Note the different time scales in the right.

not evoke an inward current or increase in membrane noise, whereas the full peptide did $(-17.2 \pm 4.3 \mathrm{pA})$, as expected. Thus, neither the sEPSP nor the inward current effect of Hcrt/Orx could be attributed to a nonspecific peptide action.

\section{Hcrt/Orx had less prevalent actions on inhibitory input to LDT neurons}

In a previous study of cultured hypothalamic neurons, Hcrt/ Orx-B was found to increase the frequency of miniature IPSCs (mIPSCs) (van den Pol et al., 1998). We therefore tested the effect of Hcrt/Orx-A and -B (1 $\mu \mathrm{M})$ on sIPSCs recorded from
LDT neurons $(n=13)$. Although effects on sIPSCs were observed, they occurred less commonly than the effects on sEPSCs. For example, an effect of Hcrt/Orx on sIPSC amplitude was not observed for any of the neurons studied, and an effect on sIPSC frequency was only observed in approximately one-half the cells (seven of 13; data not shown). Hcrt/Orx increased sIPSC frequency in four of 13 neurons (average mean interval, $61.4 \pm$ $10.9 \%$ of control), whereas in three of 13 cells, Hcrt/Orx decreased the frequency (average mean interval, $184.1 \pm 11.8 \%$ of control). Thus, Hcrt/Orx had a much more limited action on inhibitory input to LDT neurons than on their excitatory inputs. 

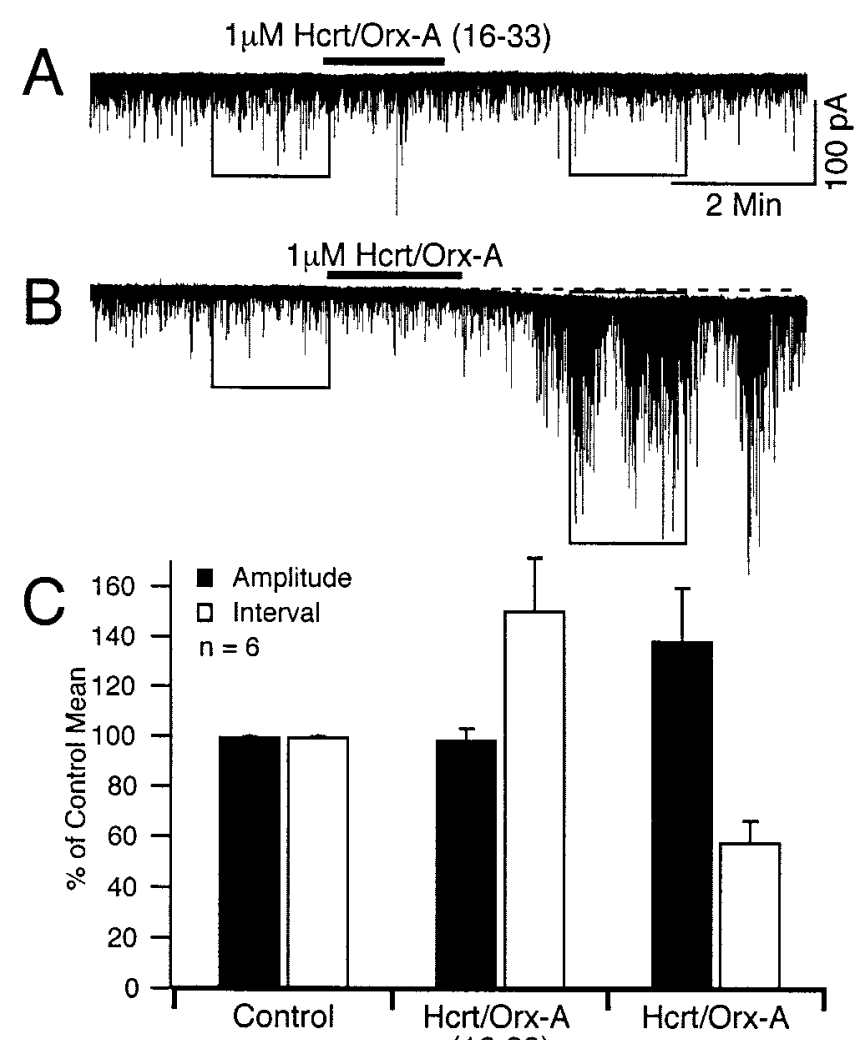

(16-33)

Figure 3. Hcrt/Orx effects were specific for the full-length peptide. Whole-cell voltage-clamp recordings $(-60 \mathrm{mV})$ were obtained using a K-gluconate internal solution and an extracellular solution containing bicuculline $(10 \mu \mathrm{M})$ and strychnine $(2.5 \mu \mathrm{M})$. A, Application of the amide fragment (16-33) of Hcrt/Orx-A did not increase the frequency or amplitude of sEPSCs. $B$, In the same neuron recorded in $A$, subsequent application of Hcrt/Orx-A produced the characteristic increase in both sEPSC amplitude and frequency, as well as an inward shift in baseline current. $C$, Average of mean inter-event intervals and amplitudes are displayed for a population of six LDT neurons exposed first to the peptide fragment and then Hcrt/Orx- $A$. Means are expressed as percentage of control values.

\section{The Hcrt/Orx-evoked increase in EPSC activity was sensitive to TTX}

To determine whether the Hcrt/Orx-evoked increase in sEPSC activity depended on the generation of $\mathrm{Na}^{+}$-dependent action potentials, we tested the effect of Hcrt/Orx on spontaneously occurring EPSCs after application of TTX (mEPSCs; $0.5 \mu \mathrm{M}$ ) on nine neurons ( $n=4$, internal K-gluconate; $n=5$, internal $\mathrm{KCl})$. In neurons recorded with internal gluconate, Hcrt/Orx-A (1 $\mu \mathrm{M})$ had no effect on amplitude or frequency distributions of mEPSCs in three of four neurons tested, although it produced an inward current accompanied by an obvious increase in membrane noise (Fig. $4 A$ ). Indeed, the noise increase in these neurons was large enough to obscure the smallest EPSCs discernable before Hcrt/ Orx application. Thus, to avoid contamination, the smallest EPSCs were excluded from the analysis. To extend the analysis to a fuller range of EPSC amplitudes, we took advantage of the observation made while recording IPSCs that the Hcrt/Orxevoked noise, and the inward current were greatly attenuated using the $\mathrm{KCl}$ internal solution. Although we did not further investigate the mechanism, this presumably resulted from the high intracellular $\left[\mathrm{Cl}^{-}\right]$interfering with $\mathrm{G}$-protein modulation of ionic conductances (Lenz et al., 1997). Five neurons were re- corded under these conditions in the presence of TTX $(0.5 \mu \mathrm{M})$, and we found that, whereas the EPSCs were similar to those measured with K-gluconate, Hcrt/Orx-A had no effect on EPSC frequency or amplitude in these recordings (Fig. 4B).

Overall, when compared with control values, neither the average mean amplitude $(98.6 \pm 3.2 \%, p=0.52$, K-gluconate; $108.4 \pm$ $5.7 \%, p=0.23, \mathrm{KCl})$ nor the average mean interval $(91.6 \pm$ $16.9 \%, p=0.75, n=4$, K-gluconate; $94.5 \pm 6.0 \%, p=0.34, n=$ $5, \mathrm{KCl}$ ) were different after Hcrt/Orx application (Fig. $4 C$ ). In the single case in which Hcrt/Orx increased the frequency, it had no effect on mEPSC amplitude. Thus, TTX blocked the Hcrt/Orx effect on EPSC frequency and amplitude in eight of nine neurons, indicating that action potentials were typically required for the Hcrt/Orx-mediated increase in EPSC activity. These data also strongly argue against the idea that the increase in sEPSC amplitude evoked by Hcrt/Orx could have resulted from a change in ionotropic glutamate receptors because the amplitude distribution of the mEPSCs remained unaltered by Hcrt/Orx.

To determine the extent to which spontaneous action potentials contributed to resting transmitter release in these slices, we examined the effect of TTX alone on SEPSC amplitude and interval distributions. Application of TTX $(0.5 \mu \mathrm{M})$ had no net effect on spontaneous EPSCs. The mean sEPSC amplitude before TTX application was $-22.3 \pm 5.3 \mathrm{pA}$, and the mean mEPSC amplitude after TTX was $-22.2 \pm 5.3 \mathrm{pA}(n=4 ; p=0.86)$. Similarly, the mean interval was $447.2 \pm 112.9 \mathrm{msec}$ before TTX and $458.9 \pm$ 122.2 msec after TTX $(n=4 ; p=0.82)$. This indicated that the resting frequency of sEPSCs did not significantly depend on the firing of action potentials in these slices and suggests that the increase in sEPSC frequency produced by Hcrt/Orx mainly results from the initiation of TTX-sensitive action potentials in glutamatergic inputs to LDT neurons.

\section{Hcrt/Orx enhanced evoked EPSCs}

To determine whether Hcrt/Orx could influence action potentialevoked synaptic transmission in addition to its ability to stimulate action potentials in afferents to the LDT, we examined the effect of Hcrt/Orx-A (300 nM) on evEPSCs. Amplitude distributions of 30-50 consecutive evEPSCs, evoked by near-minimal electrical stimuli were compared before and after application of Hcrt/Orx using Kolmogorov-Smirnov statistics. As expected, Hcrt/Orx-A produced a small inward current in these neurons (Fig. 5A). Coincident with this slow inward current was a significant increase in the mean evEPSC amplitude in three of five neurons tested (mean amplitude, $147.74 \pm 6.5 \%$ of control; $n=3$ ). This increase in EPSC amplitude was reversible and recovered as the inward current subsided (Fig. 5B). These data indicate that Hcrt/ Orx also enhanced spike-evoked EPSCs in LDT neurons.

\section{The Hcrt/Orx-evoked inward current was accompanied by an increase in membrane noise and conductance and was not dependent on extracellular calcium}

We further investigated the inward current by monitoring membrane conductance during application of Hcrt/Orx-A (300 nm and $1 \mu \mathrm{M})$. Conductance was measured as the change in current produced by constant voltage steps ( $1 \mathrm{sec}$ duration; -60 to -90 or $-100 \mathrm{mV})$ delivered in the presence of TTX (1 $\mu \mathrm{M})$, DNQX (15 $\mu \mathrm{M})$, APV $(50 \mu \mathrm{M})$, bicuculline $(10 \mu \mathrm{M})$, and strychnine $(2.5 \mu \mathrm{M})$ (Fig. 6A, inset). Under these conditions, Hcrt/Orx produced an inward current that was accompanied by an increase in membrane noise and an increase in conductance (Fig. 6A). Initially, the inward current, noise, and conductance increased in parallel, 

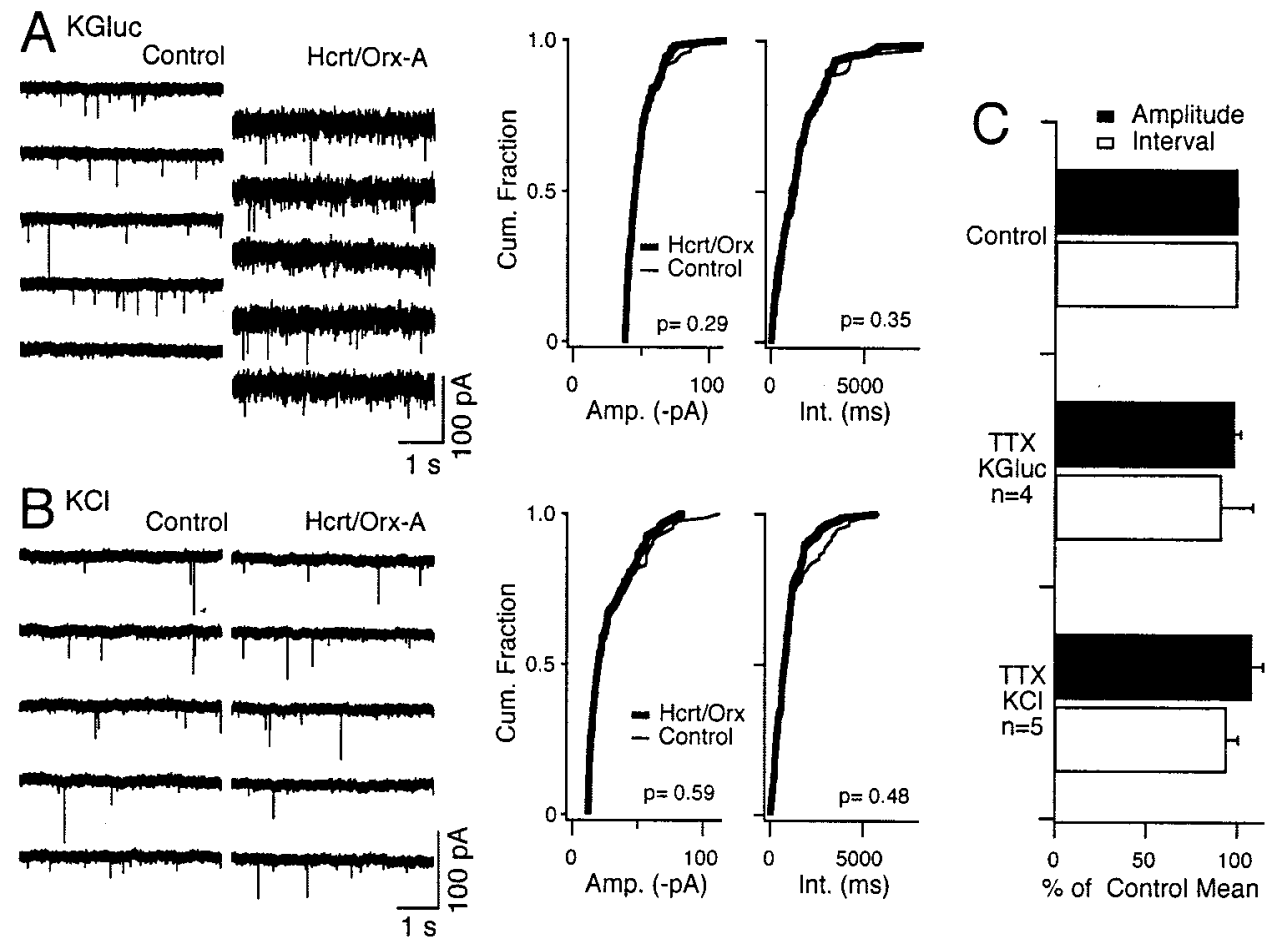

distributions of amplitude (left) and interval (right). $C$, Summary data indicating that TTX blocked both (black bars) and interval (white bars) produced by Hcrt/Orx $(1 \mu \mathrm{M})$ when neurons were recorded with either internal solution.

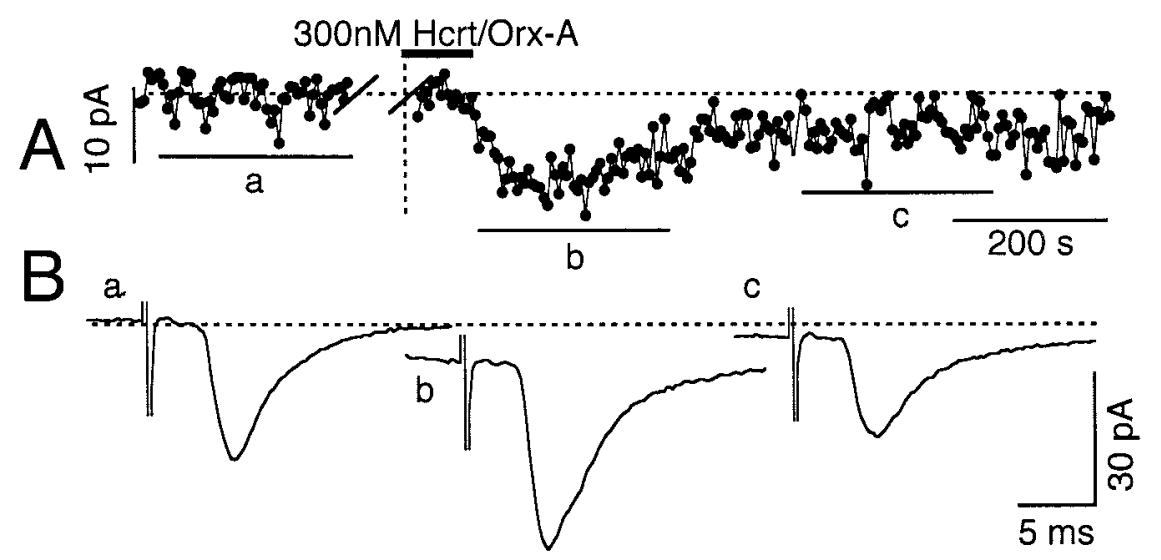

Figure 5. Hcrt/Orx increased the amplitude of evoked EPSCs. Neurons were recorded with a K-gluconate internal solution and an extracellular solution containing bicuculline $(10 \mu \mathrm{M})$ and strychnine $(2.5 \mu \mathrm{M})$. EPSCs in LDT neurons were evoked by local electrical stimulation at $0.02 \mathrm{~Hz}$. An Hcrt/Orx superfusion produced the characteristic inward shift in holding current. Epochs marked $a, b$, and $c$ indicate the control, Hcrt/Orx, and recovery conditions used to compare EPSCs. Broken line indicates time between data files. $B$, Averages of 50 consecutive EPSCs from the epochs $a-c$ indicated in $A$. The average amplitude increased from $31(a)$ to $41(b) \mathrm{pA}$ after the application of Hcrt/Orx and recovered as the Hcrt/Orx effect on membrane current subsided $(c)$.

although the conductance increase was rather variable in magnitude. At the peak of the noise increase, the membrane conductance ranged from 105.2 to $178.3 \%$ of control (mean, $133.6 \pm$ $10.1 \% ; n=9 ; p<0.005)$. In some cases, the Hcrt/Orx-evoked inward current and noise peaked and then began to subside (Fig. $6 A$ ), whereas in others, the inward current remained elevated. The conductance typically remained elevated for the duration of the recording period. The average time course of these effects is illustrated in Figure $6 B$ ( filled symbols) $(n=9)$. To determine whether these prolonged actions were specifically related to Hcrt/ Orx actions, we conducted control experiments under identical conditions $(n=4)$ but with Hcrt/Orx omitted from the superfusate (Fig. 6B, open symbols). Comparison of these control data to the Hcrt/Orx data verified that the observed changes were produced by Hcrt/Orx and were not an artifact of the lengthy recording period. To determine whether the conductance change recovered, we measured membrane conductance from cells that were freshly patched an average of 49 min after Hcrt/Orx was applied and compared this with the conductance measured from neurons not yet exposed to Hcrt/Orx. Average membrane conductance was not different between these groups $(3.2 \pm 0.2$ vs $4.0 \pm 0.4 \mathrm{nS}$; $n=34 ; p>0.05)$. Because we confirmed that these cells responded to a second application (and hence responded to the first application), we conclude that the conductance change evoked by Hcrt/Orx does recover, albeit slowly.

The finding that Hcrt/Orx increased both the membrane noise and conductance suggested that the inward current might result, in part, from the opening of "noisy" ion channels having a relatively positive reversal potential. Consistent with this idea, we observed that, after Hcrt/Orx application, membrane hyperpolarization to $-90 \mathrm{mV}$, which would increase the driving force for such channels, produced greater membrane noise than observed at $-60 \mathrm{mV}$. The increase in membrane noise associated with a voltage jump from -60 to $-90 \mathrm{mV}$ was 2.7 times larger after Hcrt/Orx application ( $p<0.05 ; n=7$ ).

The previous data suggested that the Hcrt/Orx effects may 
Figure 6. Hcrt/Orx-evoked inward current and noise were associated with an increase in membrane conductance. $A$, Membrane current noise ( filled triangles) and average membrane current (filled circles) were monitored at a holding potential of $-60 \mathrm{mV}$, and input conductance (filled squares) was monitored with voltage jumps to $-90 \mathrm{mV}$ in the presence of a solution (TTX,DABS) containing TTX $(0.5 \mu \mathrm{M})$, DNQX $(15 \mu \mathrm{M})$, APV $(50 \mu \mathrm{M})$, bicuculline $(10 \mu \mathrm{M})$, and strychnine $(2.5$ $\mu \mathrm{M})$ to eliminate action potentials and fast synaptic activity. Under these conditions, $1 \mu \mathrm{M}$ Hcrt/Orx-A still evoked an increase in noise and an inward current. These changes were accompanied by a slow increase in membrane conductance. The inset illustrates membrane voltage (top) and current (bottom) during a voltage jump from before and after Hcrt/Orx application as indicated by the arrows. Voltage and current calibration bars are $30 \mathrm{mV}$

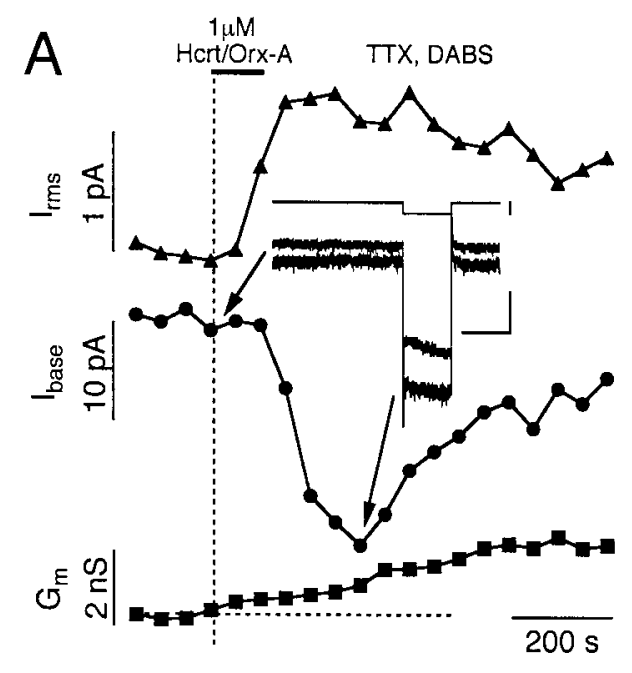

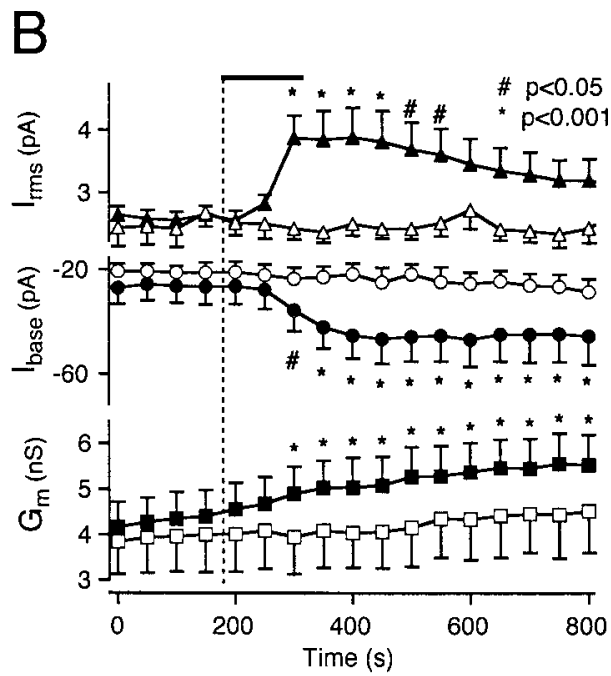

and $50 \mathrm{pA}$, respectively, and the time calibration is $1 \mathrm{sec} . B$, Time course of mean \pm SEM membrane noise $\left(I_{\text {rms }} ;\right.$ triangles $)$, current $\left(I_{\text {base }} ;\right.$ circles $)$, and conductance $\left(G_{m} ;\right.$ squares $)$ around the time of Hcrt/Orx application (filled symbols; $\left.n=9\right)$ or control solution application $($ open symbols; $n=4)$. Hcrt/Orx, but not the control solution, produced changes in these measures. ${ }^{*} p<0.001$ and $\# p<0.05$ indicate significantly different from control as determined by a repeated-measures ANOVA and post hoc testing (Bonferroni).

result from activation of Hcrt/Orx receptors located on the recorded neurons. To further test this possibility, we lowered extracellular calcium to inhibit synaptic transmission. The lowcalcium ACSF completely abolished electrically evoked EPSCs (Fig. 7A, inset). Nevertheless, Hcrt/Orx-A (300 nM) still evoked an inward current $(-32.8 \pm 10.6 \mathrm{pA} ; n=8)$ that was accompanied by an increase in membrane noise $(186.8 \pm 31.3 \%$ of control; $n=$ 8 ) as illustrated for a single case in Figure $7 A$. The average current magnitude and membrane noise evoked by Hcrt/Orx-A in normal and low calcium solutions are summarized in Figure $7 B$ and were not statistically different ( $p=0.58$, current; $p=0.15$, noise). These data demonstrate that neither calcium-dependent currents nor synaptic transmitter release are necessary for these Hcrt/Orx-A actions. Collectively, these findings suggest that both the inward current and membrane noise arose from activation of Hcrt/Orx receptors on LDT neurons.

\section{Hcrt/Orx had similar actions on both bNOS-positive and -negative LDT neurons}

As indicated in Materials and Methods, we used bNOS immunofluorescence as a marker for cholinergic neurons to determine whether the recorded neurons filled with biocytin were cholinergic. Fifty-six of 75 filled neurons were recovered, and most were bNOS $^{+}$(33 of 56), whereas the remainder (23 of 56) appeared immunonegative $\left(\mathrm{bNOS}^{-}\right)$. These bNOS neurons were found in the same focal plane with other $\mathrm{bNOS}^{+}$somata and processes, suggesting that the lack of label was not a result of poor antibody penetration. Because most cells responded to Hcrt/Orx, we compared the magnitude of the responses between immunopositive and immunonegative neurons. No statistically meaningful differences were observed between these groups, whose data are summarized in Table 1. A one-way ANOVA confirmed there were no statistical differences between responses obtained from $\mathrm{bNOS}^{+}$, bNOS $^{-}$, and the remaining neurons, which were not recovered.

\section{Hcrt/Orx produces prolonged firing of LDT neurons in the absence of fast synaptic potentials}

Finally, because the inward current evoked by Hcrt/Orx was rather small, it was unclear whether it would be large enough to produce spiking without the associated increase in excitatory synaptic drive. We therefore performed additional loose-patch extracellular recordings during blockade of fast synaptic activity with antagonists to ionotropic glutamate, GABA, and glycine receptors. Under these conditions, Hcrt/Orx-A (300 nM) still produced a prolonged increase in firing of all of the cells tested $(n=9)$ (Fig. 8A). Hcrt/Orx increased baseline firing rate from $0.23 \pm 0.1$ spikes $/ \mathrm{sec}$ to an average peak value of $1.03 \pm 0.22$ spikes/sec $(n=9)$ and induced firing in three cells that had no spontaneous action potentials before Hcrt/Orx application. Thus, the postsynaptic actions alone of Hcrt/Orx were sufficient to drive firing in these LDT neurons. We also verified that the increase in spiking produced by Hcrt/Orx was dose dependent under these conditions by allowing longer intervals than used previously between applications (Fig. 8B). These data confirmed that concentrations of $>300 \mathrm{~nm}$ were saturating, as expected from doseresponse relationships in cells transfected with Hcrt/Orx receptors (Sakurai et al., 1998; Smart et al., 1999). Indeed, the average maximum firing rate evoked by $300 \mathrm{~nm}$ Hcrt/Orx was not different from that evoked by $1 \mu \mathrm{M} \mathrm{Hcrt/Orx}(1.02 \pm 0.22 ; n=6$; $p=0.968)$.

\section{DISCUSSION}

Our findings demonstrated that Hcrt/Orx peptides influence mesopontine cholinergic neurons and suggests that these neurons and their noncholinergic neighbors are normally under the excitatory influence of hypothalamic Hcrt/Orx neurons.

\section{Actions of Hcrt/Orx on presynaptic neurons}

A previous study, using cultured hypothalamic neurons, found that Hcrt/Orx-B increased the frequency of mEPSCs and mIPSCs recorded in the presence of TTX, suggesting that these peptides can act on presynaptic terminals to increase release probability (van den Pol et al., 1998). We found that both Hcrt/Orx-A and -B increased the frequency of sEPSCs but that this effect was absent in TTX, in all but one case. Because TTX alone had a negligible effect on sEPSCs in resting slices, these findings suggest that Hcrt/Orx triggered spiking in glutamatergic afferents, which in- 

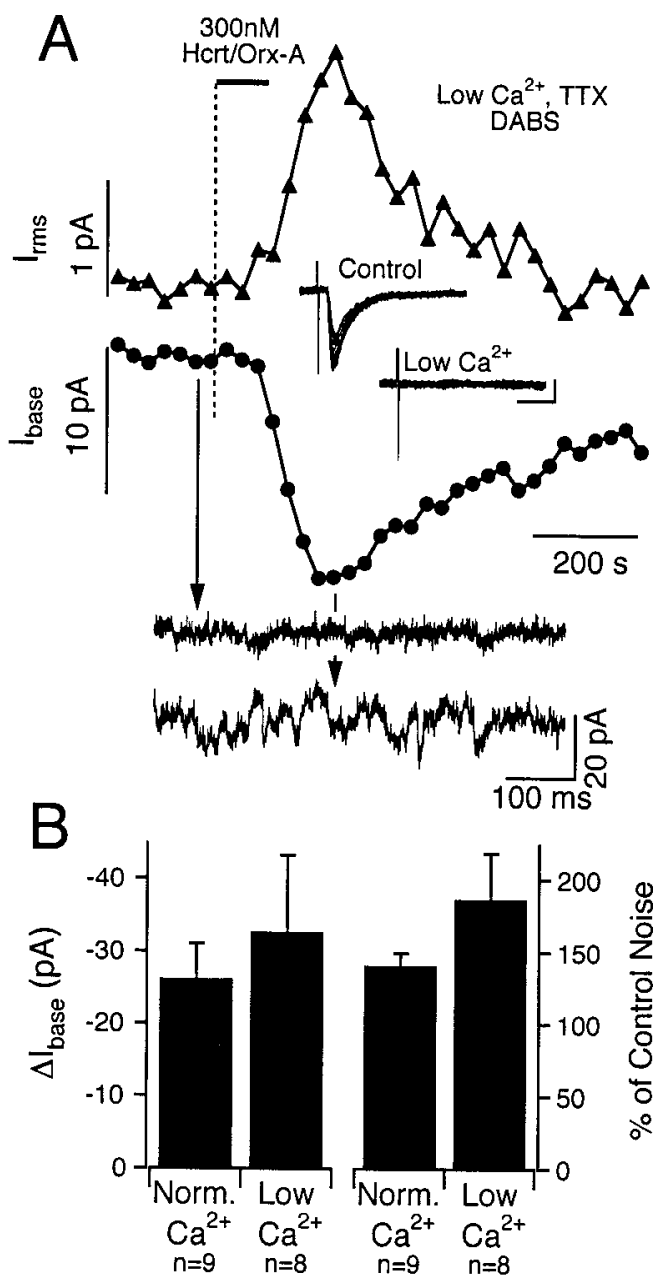

Figure 7. Hcrt/Orx-evoked inward current and membrane noise were insensitive to lowering extracellular calcium. $A$, The increase in membrane noise (triangles) and inward current (circles) evoked by Hcrt/Orx-A were resistant to solutions containing low extracellular calcium (Low $\mathrm{Ca}^{2+}, T T X$, and $\left.D A B S\right)$. Similar low $\mathrm{Ca}^{2+}$ ASCF without TTX, DNQX, and APV abolished evoked EPSCs (see inset). Calibration: $20 \mathrm{pA}$ and 10 msec. Arrows point to membrane current traces from the indicated time points before and after Hcrt/Orx application and illustrate the large noise increase produced by Hcrt/Orx under these conditions. $B$, Summary of mean inward current and noise evoked by $1 \mu \mathrm{M}$ Hcrt/Orx in calciumcontaining ACSF and by $300 \mathrm{~nm}$ Hcrt/Orx in low-calcium ACSF. The responses were not statistically different. These data strongly indicate that the inward current and membrane noise result from activation of Hcrt/ Orx receptors on LDT neurons.

creased the sEPSC frequency. This may have resulted from an action of Hcrt/Orx on the somatodendritic, axonal, or terminal regions of these glutamatergic afferents because it is not known whether their somata are located within the slices. We also found that Hcrt/Orx increased the amplitude of spike-evoked EPSCs. Because Hcrt/Orx did not change the mEPSC amplitudes and hence did not affect postsynaptic glutamate receptors, this effect also resulted from an Hcrt/Orx action on presynaptic neurons. This may have resulted from actions at the terminals to increase release probability or from actions elsewhere to increase excitability of the presynaptic afferents.

Hcrt/Orx also increased the average sEPSC amplitude, an effect also likely to result from actions of Hcrt/Orx on presynaptic neurons. First, presynaptic action potentials evoked by Hcrt/Orx would synchronize quanta released across multiple terminals aris-
Table 1. Hcrt/Orx had similar actions on $\mathrm{bNOS}^{+}$and $\mathrm{bNOS}^{-}$neurons of the LDT

\begin{tabular}{|c|c|c|c|c|c|}
\hline & \multicolumn{2}{|l|}{$\mathrm{bNOS}^{+}$} & \multicolumn{2}{|l|}{$\mathrm{bNOS}^{-}$} & \multirow{2}{*}{$\frac{t \text { Test }}{p}$} \\
\hline & Mean \pm SEM & $n$ & Mean \pm SEM & $n$ & \\
\hline $\begin{array}{c}\text { sEPSC interval } \\
(\% \text { control })\end{array}$ & $54.0 \pm 7.0$ & 11 & $34.8 \pm 10.4$ & 4 & 0.17 \\
\hline $\begin{array}{c}\text { sEPSC amplitude } \\
\text { (\% control) }\end{array}$ & $130.2 \pm 8.1$ & 11 & $146.4 \pm 29.1$ & 4 & 0.62 \\
\hline$\Delta I_{\text {base }}(\mathrm{pA})$ & $-23.7 \pm 5.0$ & 20 & $-25.0 \pm 4.8$ & 9 & 0.85 \\
\hline$I_{\mathrm{rms}}(\%$ control $)$ & $132.2 \pm 8.4$ & 17 & $144.1 \pm 11.4$ & 9 & 0.41 \\
\hline
\end{tabular}

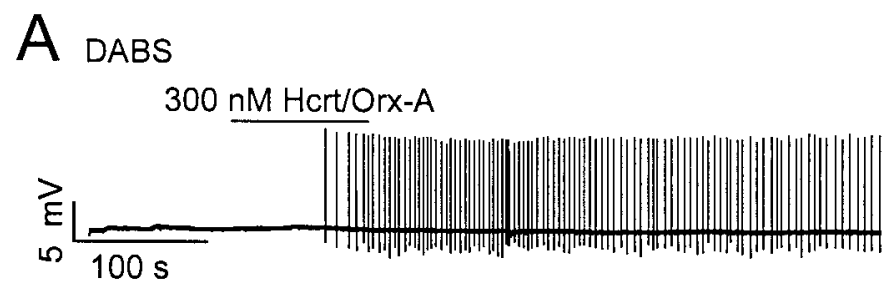

B DABS

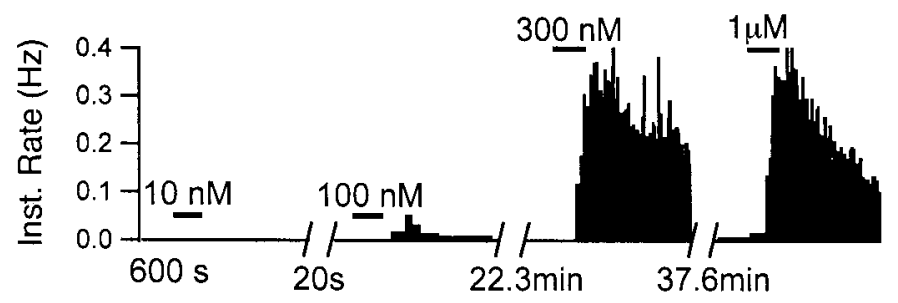

Figure 8. The Hcrt/Orx-A-mediated current is sufficient to induce spiking in LDT neurons in the absence of fast PSPs. A, Hcrt/Orx-A at $300 \mathrm{~nm}$ evoked repetitive firing in LDT neurons in the presence of a solution $(D A B S)$ containing DNQX $(15 \mu \mathrm{M})$, APV $(50 \mu \mathrm{M})$, bicuculline $(10 \mu \mathrm{M})$, and strychnine $(2.5 \mu \mathrm{M})$ to block fast glutamatergic, GABAergic, and glycinergic transmission. This demonstrated that the relatively small current observed under whole-cell conditions is functionally sufficient to produce suprathreshold depolarization in intact LDT neurons. $B$, Hcrt/ Orx-A-mediated excitation of LDT neurons was dose dependent. Hcrt/ Orx was applied during each $10 \mathrm{~min}$ epoch. Epochs were separated by the indicated times. With sufficient time between doses, a concentrationdependent action was observed.

ing from single LDT afferents and also might release multiple quanta from single terminals to produce larger sEPSCs. Second, because Hcrt/Orx increased spike-evoked EPSCs, presynaptic action potentials stimulated by Hcrt/Orx might be expected to evoke larger EPSCs. Thus, Hcrt/Orx has one or more actions on glutamatergic afferents that promote synaptic excitation of LDT neurons.

\section{Postsynaptic actions of Hcrt/Orx}

Activation of heterologously expressed Hcrt/Orx receptors increases intracellular calcium primarily by release from intracellular stores (Sakurai et al., 1998; Smart et al., 1999). In cultured hypothalamic neurons, Hcrt/Orx also elevated intracellular calcium but via a TTX-insensitive calcium influx, although no effect on membrane current was observed (van den Pol et al., 1998). In brain slices, Hcrt/Orx depolarized and evoked firing of locus ceruleus (Horvath et al., 1999) and dorsal raphe neurons (Brown et al., 2001), an effect associated with a decrease in membrane conductance based on current-clamp recordings (Ivanov and 
Aston-Jones, 2000; Brown et al., 2001). In contrast, we found that, in LDT neurons, Hcrt/Orx evoked an inward current associated with increased membrane noise and conductance, effects not reported previously. Moreover, the evoked current and noise did not require significant activation of voltage-gated calcium channels because they were insensitive to low extracellular calcium, which blocked synaptic transmission. These findings also indicate that these effects resulted from activation of postsynaptic Hcrt/ Orx receptors.

The increase in membrane noise and conductance also suggested that channel openings were involved with generating the inward current. Although other possibilities exist, the noise increase was reminiscent of the "noisy" cation current activated by acetylcholine and norepinephrine in smooth muscle (Inoue and Kuriyama, 1993; Wang et al., 1993) and by acetylcholine in entorhinal cortex (Shalinsky et al., 2001). An alternative possibility that the noise resulted from regenerative currents in distal dendrites seems unlikely. First, the increase in membrane noise did not depend on known regenerative currents. Second, the much larger sEPSCs did not trigger regenerative responses, even during Hcrt/Orx activation. Finally, membrane hyperpolarization, which would have decreased regenerative dendritic events, increased the current noise, an effect consistent with increasing the driving force for cation channels. Thus, Hcrt/OrxRs may activate a cation current similar to that observed in smooth muscle or activated by peptides in other neurons (Aosaki and Kawaguchi, 1996; Farkas et al., 1996; Kohlmeier and Reiner, 1999). Nevertheless, it appeared that more than a single ionic mechanism was involved. In some cells, the inward current was observed without increased membrane noise, and the current often outlasted the noise increase. Moreover, the conductance increase developed more slowly than either the noise increase or inward current. These observations cannot be easily reconciled with a single ionic mechanism, and additional work will be required to isolate the contributing factors.

\section{Implications for wakefulness and narcolepsy}

Mesopontine cholinergic neurons have extensive ascending and descending projections with important targets in the thalamus (for review, see Wainer and Mesulam, 1990), pontine reticular formation (Mitani et al., 1988; Jones, 1990; Semba et al., 1990; Semba, 1993), and midbrain dopamine regions (cf. Oakman et al., 1995, 1999). It is well established that activating cholinergic thalamic afferents produces EEG desynchronization (Curro Dossi et al., 1991) by suppressing slow cortical waves $(0.3-1 \mathrm{~Hz})$, delta waves $(1-4 \mathrm{~Hz})$, and spindle wave oscillations $(11-14 \mathrm{~Hz})$ (Hu et al., 1989; Steriade et al., 1993; Steriade, 1994). Stimulation also promotes gamma band $(20-40 \mathrm{~Hz})$ oscillations (Steriade et al., 1991) and fosters spatial coherence of these oscillations that outlast stimulation of the mesopontine cholinergic nuclei (Steriade and Amzica, 1996; Steriade et al., 1996). Thus, Hcrt/Orx activation of MPCh neurons is expected to promote EEG states associated with the stimulus-dependent oscillations (gamma waves) of arousal (Gray et al., 1990; Munk et al., 1996) and the tonic EEG activation characteristic of waking and REM sleep. Moreover, because cholinergic LDT neurons can drive dopamine release in the nucleus accumbens by exciting ventral tegmental area dopaminergic neurons (Forster and Blaha, 2000), Hcrt/Orxactivation of LDT should activate the limbic system and enhance motivational components of arousal, as well.

Our findings, along with previous data (Ivanov and AstonJones, 2000; Brown et al., 2001), suggest that Hcrt/Orx neurons of the hypothalamus function to activate both monoamine and cholinergic components of the ascending reticular activating system to promote EEG desynchronization and wakefulness. Indeed, focal application of Hcrt/Orx in the locus ceruleus produces arousal (Bourgin et al., 2000), and a similar effect has been reported recently for Hcrt/Orx microinjections into the cat LDT (Xi et al., 2001). Moreover, our finding that glutamatergic afferents to LDT neurons were strongly stimulated by Hcrt/Orx suggest that Hcrt/Orx neurons provide excitatory input to the glutamatergic neurons of the reticular core, as well. Thus, hypothalamic Hcrt/Orx neurons may coordinate activation of the entire ascending reticular activating system. Conversely, loss of the Hcrt/Orx peptides in narcolepsy would be expected to disfacilitate the entire ascending reticular activating system and promote the excessive daytime sleepiness that is characteristic of this disorder.

Considerable evidence also indicates that MPCh neurons play an important role in generating REM sleep (for review, see Steriade and McCarley, 1990) and that their projections to the mPRF are of particular importance for this (Quattrochi et al., 1989). Cholinergic stimulation of the mPRF rapidly produces a REM-like state (Baghdoyan et al., 1984; Gnadt and Pegram, 1986), and, in narcoleptic dogs, muscarinic stimulation of this region evokes cataplexy at doses that are benign in normals (Reid et al., 1994a). Moreover, microdialysis of atropine into the mPRF blocks the increase in attack frequency produced by systemic administration of physostigmine, a cholinesterase inhibitor (Reid et al., 1994a). Finally, Ach levels in the mPRF are elevated during these attacks in narcoleptic dogs (Reid et al., 1994b), which, along with the reported upregulation of mPRF muscarinic receptors in the mPRF (Kilduff et al., 1986), suggests that exaggerated MPCh transmission and an mPRF muscarinic supersensitivity promote cataplexy.

Based on these findings, we initially hypothesized that Hcrt/ Orx would inhibit MPCh neurons and that the loss of such inhibition in narcolepsy might explain the exaggerated MPCh transmission in cataplexy. In contrast, our findings appear to rule out this simple scheme and suggest that the loss of Hcrt/Orx input would disfacilitate MPCh neurons. One consequence of a sustained disfacilitation of MPCh is that it might trigger the upregulation of postsynaptic muscarinic ACh receptors in the mPRF, as suggested to account for muscarinic receptor changes in narcoleptic dogs (Kilduff et al., 1986). A second consequence, assuming that exaggerated MPCh activity is required to provoke cataplexy, is that one or more mechanisms must remain or be expressed in the absence of Hcrt/Orx input to drive MPCh neuron activity during these attacks. Because monoamines powerfully inhibit MPCh neurons (Luebke et al., 1992; Williams and Reiner, 1993; Leonard and Llinás, 1994), one possibility is that the loss of Hcrt/Orx excitation to monoaminergic neurons produces a disinhibition of MPCh neurons that overpowers the disfacilitation expected from the loss of Hcrt/Orx excitation. Consistent with this is the observation that locus ceruleus activity ceases during cataplectic episodes in the canine model (Wu et al., 1999). It is anticipated that future physiological studies of mouse Hcrt/Orx mutants will be of particular value in addressing this and other possibilities.

\section{REFERENCES}

Aosaki T, Kawaguchi Y (1996) Actions of substance P on rat neostriatal neurons in vitro. J Neurosci 16:5141-5153.

Baghdoyan H, Rodrigo-Angulo M, McCarley RW, Hobson JA (1984) Site-specific enhancement and suppression of desynchronized sleep 
signs following cholinergic stimulation of three brainstem regions. Brain Res 306:39-52.

Bourgin P, Huitron-Resendiz S, Spier AD, Fabre V, Morte B, Criado JR, Sutcliffe JG, Henriksen SJ, de Lecea L (2000) Hypocretin-1 modulates rapid eye movement sleep through activation of locus coeruleus neurons. J Neurosci 20:7760-7765.

Brown RE, Sergeeva O, Eriksson KS, Haas HL (2001) Orexin A excites serotonergic neurons in the dorsal raphe nucleus of the rat. Neuropharmacology 40:457-459.

Burlet S, Tyler CJ, Leonard CS (2000) Orexin peptides increase spontaneous frequency of EPSCs in mouse laterodorsal tegmental neurons. Soc Neurosci Abstr 26:566.20.

Chemelli RM, Willie JT, Sinton CM, Elmquist JK, Scammell T, Lee C, Richardson JA, Williams SC, Xiong Y, Kisanuki Y, Fitch TE, Nakazato M, Hammer RE, Saper CB, Yanagisawa M (1999) Narcolepsy in orexin knockout mice: molecular genetics of sleep regulation. Cell 98:437-451.

Curro Dossi R, Pare D, Steriade M (1991) Short-lasting nicotinic and long-lasting muscarinic depolarizing responses of thalamocortical neurones to stimulation of mesopontine cholinergic nuclei. J Neurophysiol 65:393-406.

Date Y, Ueta Y, Yamashita H, Yamaguchi H, Matsukura S, Kangawa K, Sakurai T, Yanagisawa M, Nakazato M (1999) Orexins, orexigenic hypothalamic peptides, interact with autonomic, neuroendocrine and neuroregulatory systems. Proc Natl Acad Sci USA 96:748-753.

de Lecea L, Kilduff TS, Peyron C, Gao X, Foye PE, Danielson PE, Fukuhara C, Battenberg EL, Gautvik VT, Bartlett II FS, Frankel WN, van den Pol AN, Bloom FE, Gautvik KM, Sutcliffe JG (1998) The hypocretins: hypothalamus-specific peptides with neuroexcitatory activity. Proc Natl Acad Sci USA 95:322-327.

Farkas RH, Chien PY, Nakajima S, Nakajima Y (1996) Properties of a slow nonselective cation conductance modulated by neurotensin and other neurotransmitters in midbrain dopaminergic neurons. J Neurophysiol 76:1968-1981.

Forster GL, Blaha CD (2000) Laterodorsal tegmental stimulation elicits dopamine efflux in the rat nucleus accumbens by activation of acetylcholine and glutamate receptors in the ventral tegmental area. Eur J Neurosci 12:3596-3604.

Gnadt JW, Pegram GV (1986) Cholinergic brainstem mechanisms of REM sleep in the rat. Brain Res 384:29-41.

Gray C, Engel A, Konig P, Singer W (1990) Stimulus-dependent neuronal oscillations in cat visual cortex: receptive field properties and feature dependence. Eur J Neurosci 2:607-619.

Hagan JJ, Leslie RA, Patel S, Evans ML, Wattam TA, Holmes S, Benham CD, Taylor SG, Routledge C, Hemmati P, Munton RP, Ashmeade TE, Shah AS, Hatcher JP, Hatcher PD, Jones DN, Smith MI, Piper DC, Hunter AJ, Porter RA, Upton N (1999) Orexin A activates locus coeruleus cell firing and increases arousal in the rat. Proc Natl Acad Sci USA 96:10911-10916.

Hamill O, Marty A, Neher E, Sakmann B, Sigworth F (1981) Improved patch-clamp techniques for high-resolution current recording from cells and cell-free membrane patches. Pflügers Arch 391:85-100.

Horvath TL, Peyron C, Diano S, Ivanov A, Aston-Jones G, Kilduff TS, van Den Pol AN (1999) Hypocretin (orexin) activation and synaptic innervation of the locus coeruleus noradrenergic system. J Comp Neurol 415:145-159.

Hu B, Steriade M, Deschenes M (1989) The effects of brainstem peribrachial stimulation on reticular thalamic neurons: the blockage of spindle waves. Neuroscience 31:1-12.

Inoue R, Kuriyama H (1993) Dual regulation of cation-selective channels by muscarinic and alpha 1-adrenergic receptors in the rabbit portal vein. J Physiol (Lond) 465:427-448.

Ivanov A, Aston-Jones G (2000) Hypocretin/orexin depolarizes and decreases potassium conductance in locus coeruleus neurons. NeuroReport 11:1755-1758.

Jones BE (1990) Immunohistochemical study of choline acetyltransferaseimmunoreactive processes and cells innervating the pontomedullary reticular formation in the rat. J Comp Neurol 295:485-514.

Kilduff TS, Peyron C (2000) The hypocretin/orexin ligand-receptor system: implications for sleep and sleep disorders. Trends Neurosci 23:359-365.

Kilduff TS, Bowersox SS, Kaitin KI, Baker TL, Ciaranello RD, Dement WC (1986) Muscarinic cholinergic receptors and the canine model of narcolepsy. Sleep 9:102-106

Kohlmeier KA, Reiner PB (1999) Vasoactive intestinal polypeptide excites medial pontine reticular formation neurons in the brainstem rapid eye movement sleep-induction zone. J Neurosci 19:4073-4081.

Lenz RA, Pitler TA, Alger BE (1997) High intracellular $\mathrm{Cl}^{-}$concentrations depress G-protein-modulated ionic conductances. J Neurosci 17:6133-6141.

Leonard CS, Llinás R (1994) Serotonergic and cholinergic inhibition of mesopontine cholinergic neurons controlling REM sleep: an in vitro electrophysiological study. Neuroscience 59:309-330.

Lin L, Faraco J, Li R, Kadotani H, Rogers W, Lin X, Qiu X, de Jong PJ, Nishino S, Mignot E (1999) The sleep disorder canine narcolepsy is caused by a mutation in the hypocretin (orexin) receptor 2 gene. Cell 98:365-376.

Luebke J, Greene R, Semba K, Kamondi A, McCarley R, Reiner P (1992) Serotonin hyperpolarizes cholinergic low-threshold burst neuin the rat laterodorsal tegmental nucleus in vitro. Proc Natl Acad Sci USA 89:743-747.

Marcus JN, Aschkenasi CJ, Lee CE, Chemelli RM, Saper CB, Yanagisawa M, Elmquist JK (2001) Differential expression of orexin receptors 1 and 2 in the rat brain. J Comp Neurol 435:6-25.

Mitani A, Ito K, Mitani Y, Hallanger AE, Wainer BH, Kataoka K, McCarley RW (1988) Cholinergic projections from the laterodorsa and pedunculopontine tegmental nuclei to the pontine gigantocellular tegmental field in the cat. Brain Res 451:379-402.

Munk MHJ, Roelfsema PR, König P, Engel AK, Singer W (1996) Role of reticular activation in the modulation of intracortical synchronization. Science 272:271-274.

Nambu T, Sakurai T, Mizukami K, Hosoya Y, Yanagisawa M, Goto K (1999) Distribution of orexin neurons in the adult rat brain. Brain Res $827: 243-260$

Nishino S, Mignot E (1997) Pharmacological aspects of human and canine narcolepsy. Prog Neurobiol 52:27-78

Nishino S, Ripley B, Overeem S, Lammers GJ, Mignot E (2000) Hypocretin (orexin) deficiency in human narcolepsy. Lancet 355:39-40.

Oakman SA, Faris PL, Kerr PE, Cozzari C, Hartman BK (1995) Distribution of pontomesencephalic cholinergic neurons projecting to substantia nigra differs significantly from those projecting to ventral tegmental area. J Neurosci 15:5859-5869.

Oakman SA, Faris PL, Cozzari C, Hartman BK (1999) Characterization of the extent of pontomesencephalic cholinergic neurons' projections to the thalamus: comparison with projections to midbrain dopaminergic groups. Neurosci 94:529-547.

Peyron C, Tighe DK, van den Pol AN, de Lecea L, Heller HC, Sutcliffe JG, Kilduff TS (1998) Neurons containing hypocretin (orexin) project to multiple neuronal systems. J Neurosci 18:9996-10015.

Peyron C, Faraco J, Rogers W, Ripley B, Overeem S, Charnay Y, Nevsimalova S, Aldrich M, Reynolds D, Albin R, Li R, Hungs M, Pedrazzoli M, Padigaru M, Kucherlapati M, Fan J, Maki R, Lammers GJ, Bouras C, Kucherlapati R, Nishino S, Mignot E (2000) A mutation in a case of early onset narcolepsy and a generalized absence of hypocretin peptides in human narcoleptic brains. Nat Med 6:991-997.

Piper DC, Upton N, Smith MI, Hunter AJ (2000) The novel brain neuropeptide, orexin-A, modulates the sleep-wake cycle of rats. Eur J Neurosci 12:726-730.

Quattrochi JJ, Mamelak AN, Madison RD, Macklis JD, Hobson JA (1989) Mapping neuronal inputs to REM sleep induction sites with carbachol-fluorescent microspheres. Science 245:984-986.

Reid MS, Tafti M, Geary JN, Nishino S, Siegel JM, Dement WC, Mignot E (1994a) Cholinergic mechanisms in canine narcolepsy. I. Modulation of cataplexy via local drug administration into the pontine reticular formation. Neuroscience 59:511-522.

Reid MS, Siegel JM, Dement WC, Mignot E (1994b) Cholinergic mechanisms in canine narcolepsy. II. Acetylcholine release in the pontine reticular formation is enhanced during cataplexy. Neuroscience 59:523-530

Sakurai T, Amemiya A, Ishii M, Matsuzaki I, Chemelli RM, Tanaka H, Williams SC, Richardson JA, Kozlowski GP, Wilson S, Arch JR, Buckingham RE, Haynes AC, Carr SA, Annan RS, McNulty DE, Liu WS, Terrett JA, Elshourbagy NA, Bergsma DJ, Yanagisawa M (1998) Orexins and orexin receptors: a family of hypothalamic neuropeptides and $G$ protein-coupled receptors that regulate feeding behavior. Cell 92:573-585.

Semba K (1993) Aminergic and cholinergic afferents to REM sleep induction regions of the pontine reticular formation in the rat. J Comp Neurol 330:543-556.

Semba K, Reiner PB, Fibiger HC (1990) Single cholinergic mesopontine tegmental neurons project to both the pontine reticular formation and the thalamus in the rat. Neuroscience 38:643-654.

Shalinsky MH, Magistretti J, Ma L, Alonso A (2001) Muscarinic activation of a "noisy" non-specific cation current in entorhinal-cortex layer-II neurons. Soc Neurosci Abstr 27:478.8.

Smart D, Jerman JC, Brough SJ, Rushton SL, Murdock PR, Jewitt F, Elshourbagy NA, Ellis CE, Middlemiss DN, Brown F (1999) Characterization of recombinant human orexin receptor pharmacology in a Chinese hamster ovary cell-line using FLIPR. Br J Pharmacol 128:1-3.

Steriade M (1994) Sleep oscillations and their blockage by activating systems. J Psychiatry Neurosci 19:354-358.

Steriade M, Amzica F (1996) Intracortical and corticothalamic coherency of fast spontaneous oscillations. Proc Natl Acad Sci USA 93:2533-2538.

Steriade M, McCarley RW (1990) Brainstem control of wakefulness and sleep. New York: Plenum.

Steriade M, Dossi RC, Pare D, Oakson G (1991) Fast oscillations $(20-40 \mathrm{~Hz})$ in thalamocortical systems and their potentiation by mesopontine cholinergic nuclei in the cat. Proc Natl Acad Sci USA $88: 4396-4400$ 
Steriade M, Amzica F, Nunez A (1993) Cholinergic and noradrenergic modulation of the slow (approximately $0.3 \mathrm{~Hz}$ ) oscillation in neocortical cells. J Neurophysiol 70:1385-1400.

Steriade M, Amzica F, Contreras D (1996) Synchronization of fast $(30-40 \mathrm{~Hz})$ spontaneous cortical rhythms during brain activation. J Neurosci 16:392-417.

Thannickal TC, Moore RY, Nienhuis R, Ramanathan L, Gulyani S, Aldrich M, Cornford M, Siegel JM (2000) Reduced number of hypocretin neurons in human narcolepsy. Neuron 27:469-474.

Trivedi P, Yu H, MacNeil DJ, Van der Ploeg LH, Guan XM (1998) Distribution of orexin receptor mRNA in the rat brain. FEBS Lett 438:71-75.

van den Pol AN (1999) Hypothalamic hypocretin (orexin): robust innervation of the spinal cord. J Neurosci 19:3171-3182.

van den Pol AN, Gao XB, Obrietan K, Kilduff TS, Belousov AB (1998) Presynaptic and postsynaptic actions and modulation of neuroendocrine neurons by a new hypothalamic peptide, hypocretin/orexin. J Neurosci 18:7962-7971.
Vincent S, Kimura H (1992) Histochemical mapping of nitric oxide synthase in the rat brain. Neuroscience 46:755-784.

Wainer BH, Mesulam M-M (1990) Ascending cholinergic pathways in the rat brain. In: Brain cholinergic systems (Steriade M, Biesold D, eds), pp 65-119. New York: Oxford UP.

Wang Q, Hogg RC, Large WA (1993) A monovalent ion-selective cation current activated by noradrenaline in smooth muscle cells of rabbit ear artery. Pflügers Arch 423:28-33.

Williams JA, Reiner PB (1993) Noradrenaline hyperpolarizes identified rat mesopontine cholinergic neurons in vitro. J Neurosci 13:3878-3883.

Willie JT, Chemelli RM, Sinton CM, Yanagisawa M (2001) To eat or to sleep? Orexin in the regulation of feeding and wakefulness. Annu Rev Neurosci 24:429-458.

Wu MF, Gulyani SA, Yau E, Mignot E, Phan B, Siegel JM (1999) Locus coeruleus neurons: cessation of activity during cataplexy. Neuroscience 91:1389-1399.

Xi M, Morales FR, Chase MH (2001) Effects on sleep and wakefulness of the injection of hypocretin-1 (orexin-A) into the laterodorsal tegmental nucleus of the cat. Brain Res 901:259-264. 